\title{
Transforming family positions: a conversational analysis of a family social work case
}

\author{
Carolus van Nijnatten \\ Professor of Social Work, Radboud University of Nijmegen, and Associate Professor 'Social Studies of Law', University \\ of Utrecht, The Netherlands
}

\author{
Correspondence: \\ Carolus van Nijnatten, \\ ASW/FSW, \\ University of Utrecht, \\ PO Box 80.140, \\ 3508 TC Utrecht, \\ The Netherlands \\ E-mail: c.vannijnatten@fss.uu.nl
}

Keywords: child protection, discourse analysis, family relations, family social work, family transformation

Accepted for publication: December 2004

\begin{abstract}
In a discourse and conversational analysis of a Dutch family supervision order, the transformations in family positions are examined. The parents in this case consider their son's drug addiction to be an individual problem. The family guardian succeeds in convincing them that it is a problem which concerns all the family rather than merely a personal issue for their son. By combining a positive and supportive attitude towards the parents with an unrelenting emphasis on the familial character of Marco's problems, the family guardian succeeds in getting the parents to reflect on their own position in relation to their son and their share in the problems in his life.
\end{abstract}

\section{FAMILY SUPERVISION ORDERS IN THE NETHERLANDS}

When a child lives under such conditions that there is a 'serious threat to moral or mental interests or health is seriously jeopardized, and other means have failed or will probably fail', the Dutch family court may issue a supervision order. The order obliges parents to co-operate with a family guardian who in most cases is a social worker. The family guardian has the legal assignment of 'supervising the minor, helping and supporting the minor and parent with authority, in order to avert the threat'.

The legal text expresses the double requirement made of family guardians, who represent agencies with authority over clients and at the same time attempt to share their clients' perspectives and to respect these. Care and coercion are inextricably combined, creating a tension in the work. In the first place, children under state supervision often do not receive the services to which their assessed mental health problems entitle them (Glisson 1996). Secondly, clients are often afraid that they will be treated unfairly and are anxious that social workers may abuse their powers and ignore client rights (Diorio 1992). Thirdly, social workers detest their supervisory tasks believing that good care only flourishes in confidence, which is jeopardized by a compulsory framework (Drake 1994). The outcomes of a survey among 324 family guardians show that only $20 \%$ consider that their legal tasks do not interfere with their caring tasks (van Nijnatten \& van den Ackerveken 1998). Many child welfare workers find themselves in a conflict of roles - between their role serving the courts and a professional ethic that proscribes the release of confidential information. In an earlier study, we found that social workers often disguise their restrictive powers by creating an atmosphere of openness and collaboration (van Nijnatten et al. 2001). Moreover, social workers have difficulty in determining the legitimacy and credibility of a client's assertions (Hyden 1996).

In our study, we explore the way in which a family guardian deals with this dilemma. We will show how the family guardian tries to develop a co-operative frame that will enable clients to define their situation in new terms, and how she tries to encourage the clients to give their own account. This is consistent with the idea that social work is basically a narrative and constructive activity in which the personal agency of clients is acknowledged and strengthened (De Shazer 1991; Parton \& O’Byrne 2000). Hence, the participation of clients in negotiating, conceptualizing 
and formulating the goals and means of change are a primary objective of social workers (Biehal 1993; Corby et al. 1996). From 'a not-knowing position', clients are encouraged to bring forward their expertise (Anderson \& Goolishian 1992), to abandon old patterns and to open up the future - an uncertain factor which cannot be captured in formal categories. The success of social work can often be seen in small changes that have been brought about in the way clients see themselves and their circumstances. It is important that clients themselves reconstruct their difficult situations in a more hopeful perspective.

This technique of co-construction and empowerment is also successful with mandated clients (de Jong $\&$ Berg 2001). Exercising authority is not just a matter of following formal rules and systematic protocols, but a communicative practice (Blaug 1995), in which identities and perspectives are negotiated. Both clients and social workers will try to impress (Goffman 1959), and try to secure the position of a convincing spokesperson. Clients may gain added authority by emphasizing their biographical expertise and by stressing that they have witnessed the situation to be described (Potter 1996). Professionals, on the other hand, are likely to stress their institutional affiliation and professional expertise.

Family guardians cannot rely exclusively on their legal authority, but have to build trust and psychological authority in face to face interactions with parents and juveniles. A family guardian has to work actively to be seen to be reliable. Even though clients may be hostile or suspicious and unwilling to co-operate, family guardians have to establish a relationship that will encourage them to co-operate and accept their advice. Rather than define this relationship in terms of giving and accepting help, it can best be seen as a negotiation.

\section{A CONVERSATIONAL ANALYSIS OF A SOCIAL WORK CASE}

Conversations in the context of family interventions are highly sensitive issues for parents: their performance has been disqualified and they are uncertain of the role they may be allowed to play in the future upbringing of their children. They feel that they have failed in the eyes of others. Social workers involved in child protection work therefore try, in their conversations with these parents, to limit any further loss of face. In these conversations, parents try to present themselves in a favourable light and the social worker often corroborates this presentation. For the latter there is always a tension between involvement and independence: involvement enables the social worker to assume the position of the parents and see the family problems from their point of view, while independence, on the other hand, makes it possible to maintain different standpoints (Brown \& Levinson 1978).

Communication in the context of a family supervision order has an institutional character with specific interactional patterns (Drew \& Heritage 1995; Arminen 2000). Institutional rules govern the selection of elements in the conversations as particularly relevant (Anward 1997), and their presentation as an accurate version of the situation (Potter \& Edwards 1990). In child protection, the dilemma generated by the conflicting demands of these two roles of helper and law enforcer becomes very stark (Hutchison et al. 1994; van Nijnatten 2005), generating a tension which also manifests itself in discussions between representatives of the agencies for child protection and their clients (Grossen \& Apothéloz 1998; van Nijnatten et al. 2001). In a former study we found that family guardians tended to play down the repressive nature of the intervention and tried to emphasize the necessity of co-operation (Hoogsteder et al. 1998).

\section{THE BUILDING OF NEW FAMILY RELATIONS}

The task of family guardians is a double one: to see that the development of the minor concerned is properly taken into account and that family conditions allow for the possibility of positive change. Discussions held within the frame of a supervision order may be seen as attempts to produce an agreed formulation of the way the child's care and upbringing should be guided. An important aspect of this is to discuss how the children see their parents within the family and how the parents define themselves and each other as educators. This positioning never generates a single, consistent identity but rather suggests different forms of a person in different contexts. In this article, we shall be dealing with the shifts that occur in their mutual positions in the discussions between a family guardian and a 16-year-old youth and his parents.

According to the law, a care plan should be implemented within six weeks of the supervision order being pronounced. We expect that the first discussions between the family guardian and clients will be of a diagnostic nature and related to the conclusions of the juvenile court, whereas subsequent ones are likely to 
be more orientated towards the future and towards changes needed to safeguard the development of the juvenile. The dual function of the family guardian, to establish the nature of the problems and to seek the cooperation of the family members, determines the institutional nature of family supervision communication. It affects the guardian's presentation and description of the parental positions, with regard both to each other and to their children. Parents, on the other hand, will also try to engineer a description of the pedagogical situation in the family that is as favourable to themselves as possible while at the same time trying to ensure a good working relationship with the family guardian by concurring with the way (s)he writes up the family situation.

\section{MARCO'S CASE}

The case we discuss in this article is taken from a wider study of communication between family guardians and parents. The study concerns the first four conversations of a supervision order. At the first meeting, the family guardian held a discussion with Marco and his parents. Subsequently Marco was admitted to a clinic for drug addiction, following which three further conversations were held between family guardian and parents alone.

We shall later see how the family guardian and parents try to reach a common understanding of the problems and, in the continuation of these conversations, how they try to ensure that the relationship between the parents and their son can best be realized in the future. We shall mainly pay attention to those moments when parents and family guardian reach agreement on a particular facet of the problem or when they correct or complement each other's account of it. [In the conversation transcripts, // indicates that the utterance of a speaker is given simultaneously with the utterance of the next speaker, and $(\ldots$ ? . . ) is a short unintelligible word or part of a word.]

At the first meeting, father $(\mathrm{F})$, mother $(\mathrm{M})$ and their son Marco (K) are all present. The boy has been registered with a centre for drug addiction where it is arranged that he will be admitted to cure him of his habit. The family guardian (FG) begins by introducing herself.

1. FG: um, first, let's get to know each other let's begin with you can you tell us briefly who you are. I did read eh the Board's report but that's more about what's gone wrong and of course you are someone other than just what's eh in that report
2. K: yes well I'm Marco I'm sixteen I'm just sixteen

3. FG: oh yes I read that

4. K: and well I've been given a one year supervision order

5. FG: yes

6. K: and I'm going to Berg now

7. FG: yes

The family guardian tries from the outset to put the boy's identity into a broader perspective. She suggests that the report of the juvenile court has probably singled out the negative aspects of the case and that he as a person amounts to more than is written there. This is an invitation to air any more positive aspects of the boy's character, aspects that may be important for any repositioning within the family. $\mathrm{He}$ is more than merely a drug addict. This opening by the family guardian enables Marco in his own words to say something about who he is. This is a way of encouraging the boy to collaborate. The family guardian begins the conversation with the family members by asking them how they see the nature of the problem in the family. The conclusions of the report drawn up by the juvenile court are a source of information but they are not sufficient; the family guardian will also want to know how Marco sees the problem, for this could help her prevent Marco viewing his position as merely hopeless. The family guardian thus tries to ensure that Marco will understand that his position in the family is not unalterable. In lines 4 and 6 , Marco acknowledges his position by referring to the approaching placement in Berg and later by acknowledging there is no other option, because if he does not go there he will be put into another institution.

1. FG: yes, yes, but what do you think what do you think about that it doesn't seem to me such a good prospect to know now

2. K: yes but it wouldn't be so nice for my parents to see I'm still an addict when I'm forty this seems to me at least better 3. FG: yes but it has something of come on let's do something right away I'm going to do it

4. K: we'll do it

5. FG: we'll do it

6. K: my parents'll do it too

7. FG: yes

8. K: yes

9. FG: OK I think that's OK together with all of you I think you'll need them too

The family guardian shows empathy with Marco's situation: he is facing a difficult future in a clinic for drug addicts. This gives him room to show sympathy for the parents and to put into words the consequences of his problems for them. The guardian draws attention to the individual position of Marco: ' $I$ ' $m$ 
going to do it' (3), which Marco answers with 'We'll do it' (4) and 'My parents'll do it too' (6) and thus spells out the idea that it is a joint project involving both his parents and himself. The family guardian associates herself with Marco's position and also uses the plural pronoun. Moreover, she expresses the problem to be solved in family co-operation ('together with all of you') and acknowledges that Marco will need his parents.

The social worker, in her constructive approach, shows that an adequate picture of the family situation is possible only if the individual differences of experience and the interpretation of Marco and his parents are taken into account. This is why the family guardian is interested in their view of the situation.

The family guardian follows up the conversation by delving into the work history of the parents (the mother's business, the bankruptcy of the father's firm). Here again, she gives attention to the context the family members find themselves in. She then asks parents and son to articulate verbally what they have understood a supervision order to be. This is quite unusual and another good example of the significance the family guardian attaches to seeing that the clients articulate their position for themselves. She is not content with a general affirmation but rather encourages the clients to say in their own words what a supervision order is and what its consequences are. Later on in the conversation, she urges Marco to take an active position. She minimizes the significance of any contribution that would solely reflect the point of view of parents and family guardian and emphasizes rather the importance of Marco's view of the affair.

By the time the family guardian holds a second talk with the parents, Marco has been admitted to the therapeutic centre. She asks the parents to give their version of the family history, of 'what actually happened', thus expressing a certain reservation about the contents of the juvenile court's report and indicating that the parents' expertise as witnesses of what actually happened in the family (active voice) would be appreciated (Potter 1996). The family guardian then refers to Marco's admission and finds out how the parents have experienced his departure.

1. M: that was a hard day

2. F: yes it was a bit eh that you think

3. M: we are so relieved

4. F: relieved yes because he eh because of his own feelings too

5. FG: because he rang

6. F: yes

7. M: yes that was a huge relief for both of us
8. FG: yes

9. M: because because because he was so nervous on the way so terribly nervous it was so emotional saying goodbye that was really awful I really thought oh what have I done to him 10. FG: yes

11. M: yes

12. FG: did you think then I'll just take him back again

13. M: every time I've // no absolutely not

Mother relates that the leave-taking was an emotional affair and wonders whether she has taken the right decision. It is remarkable that the family guardian presents twice her (alternative) view of the family relationships. In the fifth line, she interprets the parents' relief as a reaction to a telephone call from their son. It seems that father's relief (4) stems from observing an emotion in his son that reassured him. Mother, however, latches on to the interpretation of the family guardian and tells of the emotional leavetaking. The family guardian then suggests that mother had a hard time letting Marco go (12); mother denies this categorically.

Over the course of further contacts, the family guardian will more frequently emphasize the relation between Marco and his parents. It seems as if she wants to lead the parents to resume responsibility for their son's upbringing.

A central question seems to be whether Marco will come back to his parents after treatment or whether he will go to live on his own. Mother allows for both options. According to the family guardian, Marco wants to return home; she interprets this as an attempt to make good some of what went wrong in the past and enquires whether the relationship between Marco and his parents has been discussed at the therapeutic centre.

1. M: Marco is afraid that he'll be homesick if he sees us because on Sunday he first wanted to ring immediately very understandable

2. FG: yes

3. M: very understandable

4. FG: did you expect that he'd say that

5. M: I think so if you see he's really only a child with all his tough talk but he's still just a child

6. FG: if I were mother that would do me good to hear him say that

7. M: yes of course it does us a lot of good

8. FG: yes

9. M: yes yes however it's what I say it's just an entirely special story um we aren't a eh broken home or anything through all that stealing look he'd become unmanageable but later on it's yes it's no more yes that's all very uplifting it's

10. FG: a new start 
11. M: yes how can I say it yes we can easily make a new start every time afresh

12. FG: yes

13. M: yes but this was all necessary also this supervision order everything simply necessary in order to shake him awake again

14. FG: come on boy

15. M: yes, it's serious it's not all craziness it's not to torment or to be annoying it's just you have to

16. FG: yes yes in the discussion the question was also raised of um what they can expect from you two for instance suppose Marco wants to come home

Mother introduces Marco's anxiety about feeling homesick and for the first time she refers to her son as a child, thereby presenting herself as a parent who knows what a child needs (5). The family guardian stresses that this is a positive signal in the relationship between mother and son (6). Mother confirms this but also insists that there is nothing wrong with their family and that her son's problems are his problems alone, and that with his impossible behaviour her son had been unmanageable (9).Yet in the same turn mother says that it also doesn't fully make sense.

The positions within the family have shifted. Although mother defines Marco's addiction as his personal problem, she also sees him as a child (who needs a parent) and asserts that the family is sufficiently resilient to resume his upbringing (11), although not without an order, which she sees as necessary to move Marco in the right direction (13). The approach of the social worker is now directive, suggesting what the parents might say to their son. The family guardian endorses this by using an expression the parents themselves might have used ("come on boy') as if to encourage them to adopt a similar attitude. Then, she once again raises the matter of the parents' position.

After this episode, the family guardian stresses that if in the future things might get out of hand they must quickly get together to discuss what is best for Marco. The family guardian articulates this as a shared task: 'that then we'll get together round the table', and 'we'll just see how you think now what is important for Marco what we're going to do'. She does state clearly that she will not high-handedly intervene but that she will also want to know what the position of the parents is and hopes to be able to undertake any steps that are necessary together with them. Father and mother both wholeheartedly agree, which means that father is changing his position; it has now become a joint responsibility. Yet, this is still only a small step because the motive underlying father's agreement seems to be to prevent his son coming home again. Father and mother do not expect their son to come home once he leaves the therapeutic institution. They think that Marco is aware that they want him to finish the course of therapy. The family guardian emphasizes once again that Marco's decision to go into therapy and to stick to it derived above all from loyalty to his parents. She reformulates the parents' remark about Marco failing them. There seems to be agreement when mother admits that Marco, out of a feeling of guilt, probably wouldn't dare look them in the face. The family guardian appears to succeed in achieving intersubjectivity through the parents' reformulated account of Marco's motives and feelings. The agreement with this new formulation is an important condition for getting some movement in the positions between parents and son.

The family guardian maintains the focus on the affective dimension of the parent-son relationship. She draws attention to the positive side of a relationship that the parents have seen negatively because hitherto it was dominated by their frustration at having no solution to their son's drug addiction. This reconstruction is recognized and confirmed by the mother.

At the beginning of the third conversation, father observes that the cause of the problem lies with his son and that any change must come from him. This remark leads to a long discussion over the situation when Marco was still living at home. Father relates at length how frustrating Marco's upbringing was for him and how eventually he lost any hold on his son. Father found it painful to see how difficult it was for his son at the beginning of the treatment and praises his courage for sticking to it. The conversation then turns to Marco's early childhood, the diagnosis of social-emotional disturbance and the condition of the family at the time that mother gave birth to a stillborn child and had to spend some time in hospital.

1. F: it finished badly with the fourth and then Marco's diarrhoea was also growing worse

2. FG: yes yes

3. M: yes because of course that also had an effect then a home help came now that was worse than useless

4. FG: yes a stranger in the home

5. $\mathrm{M}: / /$ stranger in the home //

6. FG: // and when you you // came home did he come to you then?

7. M: at first he didn't want to know me and then of course later he was won over to me again completely

8. FG: yes

9. M: yes, sure 
10. FG: yes (.) he had to get used to it again

11. M: yes yes I think that that sorrow also a long time ugh I think a child is really for two years unconsciously very active it its emotional development that's a very sensitive age

12. FG: yes yes (.) it was a very insecure situation and

13. M: yes running from pillar to post we had a week's holiday and he was always I think that he then began to suffer something of the I'm always shut out we went for a week's holiday and that was three weeks before [name of deceased baby] was born and then we also took him for a week to my mother's my father enjoyed really him a week but he went so when we came home again you never know what's going on in a child like that

14. FG: $\mathrm{mm}$

15. M: then we were at home for three weeks and then his world was turned upside down again

16. FG: yes

17. M: because then I was taken away in the ambulance and he went back home and then you're shoved to one side again 18. FG: yes yes

19. M: and I think it affects such a small child more if it

20. FG: yes

21. M: and then with his difficult character that that (.)

22. FG: he was already always an emotional child

23. M: yes

24. FG: who was always wanting care and attention

25. M: yes yes

26. FG: the diarrhoea crying

27. M: yes, he simply always wanted my attention

28. FG: yes yes daddy and mummy

29. M: that's why I'd started it because I think that can really transform so much

30. FG: yes yes (.) yes and it I also think that it can have a great deal to do with it in any case it had its effect all around him it's left its influence on your family

31. M: yes

32. FG: because I assume that as parents you would have become very different

33. M: yes

34. FG: after going through something like that (.) you were different parents before the baby was born than you were afterwards I think

35. M: yes absolutely

36. FG: yes

37. M: with everything you know we really had our share of misfortune huh with the unemployment we have led a life of 38. FG: yes you really have persevered

39. M: yes yes we never give up

The parents once again depict Marco as a problem child but they themselves now set the portrait against a background of their family history in which, over a period of five years, four children were born, the last of which was stillborn. When the family guardian asks about Marco's attachment, mother replies that at first her son didn't want anything to do with her but that she was subsequently able to repair the bond. In lines 10 and 12 the family guardian articulates the developmental context of Marco as a young child, and in lines 22 and 24 uses this to explain his current condition. She subsequently rephrases 'difficult' as 'emotional' and as seeking care and attention, and tries to draw out the contextual relation of Marco's problems by directly associating the psychosomatic diarrhoea with the crying (26). In a heavy tone, mother acknowledges that her son was always demanding (27), thus admitting in general terms that family events have had their effect on Marco. The family guardian reacts by suggesting that these must have had their impact also on the family (30) and on their performance as parents (32 and 34). The family guardian makes it easier for the parents to acknowledge this by complementing them on their fortitude. Mother readily assents to this reconstruction.

In the fourth conversation the family guardian discusses the care plan with the parents. She does not immediately respond to mother's quick affirmation and wants to make sure that the parents really approve of the text of the plan. Father recounts that, in a talk with their son, it emerged that Marco had a record of offences of which the parents were unaware. The parents observe that there have been failures of communication. The family guardian does not contradict the parents and from time to time touches on this subject.

1. FG: // but what // what did you find hardest then? you said just as at first // that was very hard

2. $\mathrm{F}: / /(\ldots$ ? . . ) // very hard even for him it's very emotional

3. FG: you found it completely distressing

4. F: yes

5. M: distressed the rest of the day

6. FG: yes

7. M: the whole night too

8. FG: what exactly was so distressing

9. M: well I I still have the feeling that I've failed or something

10. FG: hm and that he if he says that

11. M: yes that's very painful

12. FG: yes

13. M: that a child has found it so difficult

The parents immediately respond positively to the family guardian's change of direction in the conversation. Initially, in their eyes, the guilt lay with Marco but now, not only can they express their feelings of distress at seeing their son in such circumstances, mother is also able to relate this to her own failure. The mother can put herself in her son's position and for the first time sees that his problems may also be the consequence of problems in the family. She is now 
capable of detaching Marco's own subjective position - with all its associated friction and strife - from her own desires.

1. F: it's a good school, a good training for him (...? . . )

2. M: I think it's not only good training for him

3. F: and for us too of course because I repeatedly learn from things like this

4. FG: after all it's not nothing for you to sit here without

Marco because he's in Berg?

5. F: it's not pleasant either

6. FG: no

7. F: but on one hand it gives you a bit of peace you know like these weekends

8. FG: you are confident, huh // in him // that it'll all come right?

9. F: // eh I // I have confidence in it and especially now that the holidays are behind us

10. FG: yes that's also true and are you confident?

11. M: hmm yes I'm beginning to get some confidence

12. FG: yes hm

13. F: I just think that he that eh he'll see it through

14. FG: yes he's going to manage it you think

15. F: yes

16. FG: you see your own // future // fine in a year from now eh 17. F: // I think // yes I'd say that and that's why um it's the turn for all of us to work for his homecoming of course and that

By means of a pointed question, the family guardian raises the question of the parents' expectations regarding the future and explicitly asks them whether they have confidence in it (10). Father says he is confident about the future and that it will be a learning experience for all of them. Mother assents with slight hesitation (11). The family guardian does not pursue the meaning of this hesitation but instead presses on to introduce a number of significant reformulations in the dialogue with father. When father says that he thinks Marco will see the treatment through (13), she reformulates this as father thinking that Marco will manage (14), which is a much broader way of construing the outlook. In the next line, she sets a time limit of one year to this prospect (16). Father replies that it is a joint responsibility to work for his son's return home, upon which the family guardian again refers to the therapeutic sessions, which father endorses. Both confirm this. The scenario for the future is outlined in a few sentences: if the members of the family agree to participate in these therapeutic sessions, Marco's returning home is a realistic possibility within one year.

At the end of the fourth conversation, the family guardian reads back to the parents what has tran- spired: that they have openly discussed the whole problem of their son and that she believes this to be a strong point for both parents and son. In her view, there is therefore a good chance they will manage. The family guardian expressly refers to 'both of you' possessing these strong aspects, allowing the matter to be presented as a family affair. It is possible to redeem the situation as long as problems can be communicated in an open atmosphere. On this upbeat note the conversation ends.

\section{CONCLUSION}

The formulations of the care plan say that the parents have requested family supervision because they are at a loss to know how to deal with their son's behaviour. In the course of the conversations, they have also tried to convince the family guardian that the drug addiction is a problem of their son alone and that the solution lies in treatment in a rehabilitation centre. The family guardian has offered them another view of Marco's situation and by the end of the first four conversations she would seem to have succeeded in getting this across. In the fourth conversation the family guardian reads to the parents the way she wishes to formulate the objectives in the plan of assistance:

FG: Marco the juvenile has been placed outside the home in a professional provision for a period further to be determined and emphatically qualifies to be placed back when the pedagogical situation is suitable. The parents will be given specific support, guidance or treatment that has now been set in train. I think that is also the aim. Then I have formulated a number of aims and objectives below that have actually been set in motion. Marco wants to kick his addiction that is clear. Placed at Berg. For how long is not yet clear. Below that contacts in the family network, that is actually visits by you as long as the supervision order lasts because once the supervision order is finished then I won't be coming any more so we'll not be discussing it any more. Reorienting toward fulfilment of parental responsibility in the present and future situations in these conversations with the parents, that's what we just said. How was that? You're very easy you know.

The family guardian has succeeded in putting the individual problem of Marco in the context of the family and more significantly in obtaining the assent of the parents for this point of view. According to the plan, the parents will get specific support, supervision or treatment. The strength of the family will have to be gauged again to see whether a placement back in the home would in due course be possible and 
whether the parents are able to resume the upbringing of their son without the support of a family guardian.

Over the course of four conversations, the family guardian has succeeded in convincing the parents that Marco's problem of drug addiction is not unconnected with the situation in the family. The relationship between parents and son is now seen as part of the problem and the parents agree with a care plan in which they also will be the subjects of supervision.

The conversations analysed here are an exchange of contending arguments rather than a straightforward argument between two parties. The result of the conversations is not due to superior argumentation on the part of the family guardian but to the joint production of a new understanding of the problem within the family. The family guardian and the parents have together reached the same point of view: that the parents should look at their son's problems differently. This new understanding of the family dynamics is the end-point of a series of collaborations between parents, Marco and the family guardian. Yet, at the same time, professional and clients co-operate in an asymmetric institutional context in which both authority and empathy are instruments used to achieve the desired changes.

The family guardian's approach is from the beginning directed towards developing a common frame together with the parents and juvenile. She does not assume that the findings of the juvenile court are the only objective starting point or that wisdom concerning the way in which problems are resolved lies exclusively in predetermined categories of upbringing, development and problems of addiction. Instead, she keeps trying to co-construct a new definition of the problem of Marco in terms of family relations. The social worker started from the idea that you can only realize effective changes where these are based on an understanding that is shared by the clients concerned. She lets it be known that different views of reality can coexist and that she can only work well if she is fully aware, not only of what the juvenile court has judged the situation to be, but also of how the parents and Marco look at the problem and its solution.

This approach is constructive and expressed in tactics and strategies that reveal themselves in the conversations in slight turns of phrase and reactions. The most frequently used method was to reformulate the contributions from Marco and his parents so as to give them a different direction. These reformulations were presented as supplementary rather than as corrections, and this seems to have been an important reason for the success of this approach. The family guardian has taken great care with the parents' reactions when presenting Marco's problems as in part a reaction to other problems in the family. She has tried not to offend the parents or to cause unnecessary loss of face. Her reformulations seem on a few occasions to go too far for the parents, and on each such occasion they stressed the individual nature of their son's problems. At no time does the family guardian confront them directly. Sometimes a new formulation is sought while at the same time it is emphasized that parents and children have had to deal with major problems and that the parents have shown considerable courage in carrying on. In this way, the parents are never given the idea that they are guilty of causing their son's problems. At the same time, they are offered the chance of saying that they wish to resume the responsibility for his upbringing. A picture of the family has thus been built up in which, in the past, they have had to handle several major problems (the death of a child, unemployment) that no-one in the family could help, but which have nonetheless had a seriously negative effect on Marco. By accentuating the opinion that the parents have been brave to see through these difficult times, she enables the parents to feel recognized in their attempts to keep the family together, and allows them to see that Marco as a child has also suffered under these difficult circumstances. By combining a positive and supportive attitude towards the parents with an unrelenting emphasis on the familial character of Marco's problems, the family guardian has succeeded in getting the parents to reflect on their own position in relation to their son and their share in the problems in his life.

\section{REFERENCES}

Anderson, H. \& Goolishian, H. (1992) The client is the expert: A not-knowing approach to therapy. In: Therapy as Social Construction (eds S. McNamee \& K. Gergen), pp. 25-39. Sage, London.

Anward, J. (1997) Parameters of institutional discourse. In: The Construction of Professional Discourse (eds B. Gunnarsson, P. Linell \& B. Nordtberg), pp. 127-150. Longman, London.

Arminen, I. (2000) On the context sensitivity of institutional interaction. Discourse and Society, 11, 435-458.

Biehal, N. (1993) Changing practice: participation, rights and community care. British fournal of Social Work, 23, 443-458.

Blaug, R. (1995) Distortion of the face to face: communicative reason and social work practice. British fournal of Social Work, 25, 423-439.

Brown, P. \& Levinson, S. (1978) Universals in language use: politeness phenomena. In: Questions and Politeness: Strategies 
in Social Interaction (ed. E. Goody), pp. 56-289. Cambridge University Press, Cambridge.

Corby, B., Millar, M. \& Young, L. (1996) Parental participation in child protection work: rethinking the rhetoric. British fournal of Social Work, 26, 475-493.

De Shazer, S. (1991) Putting Difference to Work. Norton, New York/London.

Diorio, W. (1992) Parental perceptions of the authority of public child welfare caseworkers. Families in Society: The fournal of Contemporary Human Services, 4, 222-235.

Drake, B. (1994) Relationship competencies in child welfare services. Social Work, 5, 595-602.

Drew, P. \& Heritage, J. (1995) Talk at Work: Interaction in Institutional Settings. Cambridge University Press, Cambridge.

Glisson, C. (1996) Judicial and service decisions for children entering state custody: the limited role of mental health. Social Service Review, 70, 257-279.

Goffman, E. (1959) The Presentation of Self in Everyday Life. Doubleday, New York.

Grossen, M. \& Apothéloz, D. (1998) Intelligence as a sensitive topic in clinical interviews promoted by learning difficulties. Pragmatics, 8, 239-254.

Hoogsteder, M., van Nijnatten, C. \& Suurmond, J. (1998) Communication between family supervisors and mandated clients: an analysis of videotaped interactions. International fournal of Child and Family Welfare, 3, 54-71.
Hutchison, E., Dattalo, P. \& Rodwell, M. (1994) Reorganizing child protective services: protecting children and providing family support. Children and Youth Services Review, 16, 319338.

Hyden, L. (1996) Applying for money: encounters between social workers and client - a question of morality. British fournal of Social Work, 26, 843-860.

de Jong, P. \& Berg, I. (2001) Co-constructing cooperation with mandated clients. Social Work, 46, 361-375.

van Nijnatten, C. (2005) The presentation of authority in encounters with mandated clients. Advances in Sociology Research, in press.

van Nijnatten, C. \& van den Ackerveken, M. (1998) De Ondertoezichtstelling in de Ogen van Gezinsvoogden (The Family Supervision Order in the Eyes of Family Supervisors). ISOR, Utrecht. van Nijnatten, C., Hoogsteder, M. \& Suurmond, J. (2001) Communication in care and control: institutional interactions between family supervisors and parents. British fournal of Social Work, 31, 705-720.

Parton, N. \& O'Byrne, P. (2000) Constructive Social Work: Towards a New Practice. Macmillan, Houndmills/London.

Potter, J. (1996) Representing Reality: Discourse, Rhetoric and Social Construction. Sage, London.

Potter, J. \& Edwards, D. (1990) Nigel Lawson's tent: discourse analysis, attribution theory and the social psychology of fact. European Fournal of Social Psychology, 20, 405-424. 